\title{
Riský shift and social exchange in dyads
}

WALTER C. SWAP and HAROLD MILLER, The University of Michigan, Ann Arbor, Mich. 48106

A previous study has indicated that dyads, unlike larger groups, do not exhibit the "risky-shift" phenomenon. In the present investigation, some dyads were changed after each discussion, while other Ss remained paired with the same partner for all discussions. It was hypothesized that "stable dyads" would exhibit social-exchange behavior that would inhibit consistent shifts in risk taking following group discussion, while "reconstituted dyads" would exhibit the risky shift. Further, social-exchange behavior in the reconstituted dyads should be evidenced by greater influence and more consistent influence by group members. The data for male Ss confirmed the hypotheses, while female dyads shifted consistently in the risky direction, regardless of the stability of the dyads.

Investigators have consistently found that, for groups with from three to seven members, group decisions involving risky or conservative alternatives are, with few exceptions, more risky than the average initial riskiness of the group members. One recent study (Teger \& Pruitt, 1967) has demonstrated a direct relationship between amount of "risky shift" and group size. The greatest shifts were found for groups of five, while the smallest occurred in groups of three. This relationship has received support from $\operatorname{Rim}(1967)$, who failed to find a risky shift, using male dyads as decision-making groups.

The typical risky-shift experiment utilizes a number of Wallach \& Kogan's (1959) "life-choice dilemmas," in which Ss are asked to advise a central character who is faced with a choice between relatively safe, yet unrewarding, outcomes, and relatively risky, yet rewarding, outcomes. Individual Ss complete all of the situations, then meet in groups to attempt to come to a consensus on each situation. It is not unu sual for group leaders to emerge who, for one reason or another, influence the other members. In fact, one theory to account for the risky shift (see Brown, 1965) assumes that the "leader" or "most influential member" is generally quite risky in orientation, and is thus able to lead the group to a risky consensus. There are certain forces, however, that would tend to counteract the consistent influence of one group member. Assuming that no complementary patterns of such personality types as dominance-submissiveness exist in most of the groups, there should be exhibited a social-exchange pattern, whereby a member who has found himself complying consistently will feel pressure to be assertive, while the generally ascendant member will be forced to relinquish power occasionally to maintain the esteem of fellow group members [cf. Homans's (1961) "rule of distributive justice" and Jones's (1964) concept of "ingratiation"]. This pattern should be strongly evident, however, only in those groups which have a stable membership. If the groups are reconstituted for each discussion, there will be no opportunity for Ss to observe the relative dominance of other members; hence, a dominant $S$ could be assertive in each of his groups without running the risk of endangering his prestige. It is possible, however, that a limited amount of social exchange of power might be evident in groups that are scrambled after each discussion; a $\mathrm{S}$ who has consistently been argued away from his initial position might eventually wish to assert himself.

The present investigation is an attempt to discover whether or not, in fact, the risky shift may occur in dyads. In this respect, the study is a replication of Rim's (1967). Further, we wish to suggest some mechanism that might account for the presence or absence of the risky shift in dyads. Specifically, we hypothesize that the risky shift will occur only in those dyads that are reconstituted for each discussion and group decision. In his experiment, Rim kept the dyads intact for all group discussions. 1 Thus, the hypothesis would support Rim's results when his conditions are met, but would predict a risky shift when stable dyads are not used. Secondly, we hypothesize that in stable dyads, there should exist pressures away from a consistent, transsituational influence by individual members. In reconstitu ted dyads, however, individual $S s$ will be more consistently either influential or noninfluential.

\section{SUBJECTS}

Fifty-three Ss, 25 males and 28 females, were used. All were students in an introductory psychology course at a large Midwestern university. Twenty-nine were members of dyads that were reconstituted after each discussion, while, one semester later, 24 were members of fixed dyads. Each $S$ was paired with a member of the same sex. MATERIALS

Four of the original Wallach and Kogan (1959) situations were used. Ss were asked to advise a hypothetical person who was faced with a dilemma. Ss could advise the person to adopt a desirable, but risky, alternative or a conservative alternative, in which case a less desirable outcome is made more palatable by being less likely to fail. A sample situation, with the accompanying response scale, follows:

Mr. A, an electrical engineer, who is married and has one child, has been working for a large electronics corporation since graduating from college 5 years ago. He is assured of a lifetime job with a modest, though adequate, salary and liberal pension benefits upon retirement. On the other hand, it is very unlikely that his salary will increase much before he retires. While attending a convention, Mr. A is offered a job with a small, newly founded company which has a highly uncertain future. Mr. A would prefer to take the new job, if the company should survive the competition of the larger firms, since it would pay more money to start and would offer the possibility of a share in the ownership.

Imagine that you are advising Mr. A.

How high would the chances that the company will prove financially sound have to be before you would recommend that Mr. A take the new job?

Mr. A should take the new job, if the chances are at least

9 in 10 that the company will prove

financially sound

8 in 10

7 in 10

6 in 10

5 in 10

4 in 10

3 in 10

2 in 10

1 in 10 that the company will prove financially sound

The other situations involved a college football team captain who can tie the game with an almost certain-to-succeed play, or try to win with a more risky play; a research physicist who must decide on whether to work on an important problem that, if it failed, would leave him with little to show, or work on a series of less ambitious, but more certain, projects; a couple contemplating marriage, but plagued with sharp differences of opinion that may portend marital disaster.

The first three of these situations showed, on the basis of pretesting, a tendency to exhibit the risky shift, while the latter tends to be a conservative situation. Since Rim used situations that have been shown to be risky, only data from the first three situations are analyzed, in an effort to make them more comparable to Rim's data. However, in analyzing influence of 
Table 1

Mean Risk-Scores for Initial, Group, and Final Decisions 1

\begin{tabular}{lccccc}
\hline & Initial & Group & Final & $\begin{array}{c}\text { Initial } \\
\text {-Group }\end{array}$ & $\begin{array}{c}\text { Initial } \\
\text {-Final }\end{array}$ \\
\hline & & \multicolumn{5}{c}{ Stable Dyads } \\
Males & 3.77 & 3.53 & 3.40 & 0.24 & 0.37 \\
Females & 4.79 & 4.38 & 4.45 & $0.41^{* * *}$ & $0.34^{*}$ \\
& & \multicolumn{5}{c}{ Reconstituted Dyads } \\
Males & 3.71 & 3.24 & 3.29 & $0.47^{* *}$ & $0.42^{*}$ \\
Females & 3.76 & 3.24 & 3.36 & $0.52^{* * *}$ & $0.40^{*}$ \\
\hline
\end{tabular}

I A lower number indicates greater risk

${ }_{p}<.05 ; *{ }^{*}<<.025 ; * * * p<.01 ;$ all t-tests are one-tailed

members, data from all four situations are used. Social exchange should operate most strongly over a large number of sitatuions, and since the crucial experience for $\mathrm{a} S$ is the feeling that he is being unduly influenced, it should not matter whether the situation is conservatively or riskily orien ted.

\section{PROCEDURE}

The Ss were handed instruction sheets, in which the life-choice dilemmas were explained, and an example given. Ss then completed each of the four situations individually. No time limit was assigned. The completed questionnaires were collected and fresh copies handed out. Ss were then assigned randomly to a person of the same sex; each dyad discussed the first situation and came to a consensus, if possible, although consensus was not strictly enforced. When consensus was not reached, the mean of the two members' decisions in the group was taken as the group decision for purposes of analysis. For the "stable dyad" groups, the same two people discussed each of the four situations together. For the "reconstituted dyad" groups, new dyads were arbitrarily established after each group decision. No two Ss appeared together in more than one dyad in this condition. After all group decisions had been reached, the completed questionnaires were collected, fresh ones

Table 2

Number and Direction of Shifts from Initial-Group and Initial-Final

\begin{tabular}{|c|c|c|c|c|}
\hline & \multicolumn{2}{|c|}{$\begin{array}{l}\text { Stable } \\
\text { Dyads }\end{array}$} & \multicolumn{2}{|c|}{$\begin{array}{c}\text { Reconstituted } \\
\text { Dyads }\end{array}$} \\
\hline & $\begin{array}{l}\text { Initial } \\
\text {-Group }\end{array}$ & $\begin{array}{l}\text { Initial } \\
\text {-Final }\end{array}$ & $\begin{array}{l}\text { Initial } \\
\text { Group }\end{array}$ & $\begin{array}{l}\text { Initial } \\
\text {-Final } \\
\end{array}$ \\
\hline \multicolumn{5}{|l|}{ Males } \\
\hline Risky & 9 & 9 & $13^{* *}$ & 11 \\
\hline Conservative & re 4 & 4 & 4 & 4 \\
\hline No Change & 2 & 2 & 4 & 6 \\
\hline \multicolumn{5}{|l|}{ Females } \\
\hline Risky & $15^{* * *}$ & $13^{* *}$ & $11^{*}$ & 11 \\
\hline Conservative & ve 2 & 2 & 3 & 4 \\
\hline No Change & 4 & 6 & 7 & 6 \\
\hline
\end{tabular}

distributed, and final individual decisions made. These were collected, and the experiment was terminated.

\section{RESULTS}

Table 1 summarizes the mean risk scores by sex for each of the two conditions and the shifts in risk taking from initial-to-group and from initial-to-final decisions. $A$ initial-to-group and from initial-to-final decisions for males in the reconstituted

Since Rim used the sign test to analyze his results, Table 2 is included for purposes of comparison. Roughly equivalent results are obtained as for Table 1, except that the initial-to-final shifts for males and for females in the reconstituted-dyads condition are no longer significant.

Further results bear on the second score was calculated for each $\mathrm{S}$. This score was obtained by subtracting the number of scale units that the $S$ moved in reaching a group decision from the number of units that his partner moved. Hence, if S A moved from minimum odds of $2 / 10$ to $5 / 10$, while B moved from $6 / 10$ to $5 / 10$, A's influence score would be -2 , since he moved 2 more units than B, while B's influence score would be +2 . For each $S$, these scores were summed across situations. The lower the sum, the greater the social exchange. The mean score for males in the stable dyad group was 1.2, while for the reconstituted dyad males the mean was 2.13 , a difference associated with a $t$ score of $2.157(p<.05)$. Further, for the stable dyad males, out of 30 possible alternations in sign (i.e., a shift across situations from being influencer to being influenced, or vice versa), 10 were actually obtained, while only 5 out of 41 were observed for the reconstituted dyad males $\left(\chi^{2}=4.64, \mathrm{df}=1, \mathrm{p}<.05\right)$. Results for female Ss failed to differentiate the two conditions on either of the two social-exchange measures. DISCUSSION

Rim's condusions regarding the absence significant risky shift is demonstrated from dyads, and for females in both conditions. hypothesis. For each situation, an influence of risky shift in dyads is supported when Rim's procedure is duplicated. A dyad that remains stable across situations seems to lend itself to the social exchange of influence. As was pointed out, members of such dyads are less likely to be consistently either influential or noninfluential. When dyads are reconstituted for each discussion, however, a significant risky shift was observed, and certain members emerged clearly as leaders and others as followers. More consistent pattems of member influence characterize these groups. The result in the stable dyads is an inhibition of the risky shift that appears in the reconstituted dyads.

It is important to note that these relationships hold only for the male Ss in our sample. In his study, Rim used only males. ${ }^{1}$ In the present study, women uniformly showed a risky shift, and no differences were observed in the individual member's influence patterns across conditions. A partial explanation for these sex differences may be that the females in our sample seemed much less likely than males to reach a consensus. Failure to reach consensus occurred eight times in female dyads, while all male dyads reached consensus. The fact that the females apparently did not feel a pressure to conform to the influence attempts by their partners would at least partially explain the fact that the two conditions of dyad formation were not differentiated by their influence pattems, although this does not explain why women were more likely than men to refuse consensus.

Rim's Ss were Israelis, with a mean age of 32 , and were soldiers and civil-service officials, while our Ss were primarily college sophomores. The fact that his results were replicated in the appropriate experimental condition augurs well for both the generalizability and the potential importance of the results.

\section{REFERENCES}

BROWN, R. Social psychology. Glencoe, Ill.: Free Press, 1965.

HOMANS, G. Social behavior: Its elementary forms. New York: Harcourt, Brace \& World, 1961.

JONES, E. Ingratiation: A social psychological analysis. New York: Appleton-Century-Crofts, 1964.

RIM, Y. Decisions involving risk in dyads. Acta Psychologica, 1967, 26, 1-8.

TEGER, A., \& PRUITT, D. Components of group risk taking. Journal of Experimental Social Psychology, 1967, 3, 189-205.

WALLACH, M., \& KOGAN, N. Sex differences and judgment processes. Journal of Personality, $1959,27,555-564$. NOTE

1. Rim, Y. Personal communication, 1969. 